\title{
Role of Repetitive Nine-Residue Sequence Motifs in Secretion, Enzymatic Activity, and Protein Conformation of a Family I.3 Lipase
}

\author{
HYUN-JU KWON, ${ }^{1}$ MITSURU HARUKI,${ }^{1}$ MASAAKI MORIKAWA, ${ }^{1}$ \\ KENJI OMORI, ${ }^{2}$ AND SHIGENORI KANAYA ${ }^{1 *}$ \\ Department of Material and Life Science, Graduate School of Engineering, Osaka University, 2-1 Yamadaoka, \\ Suita, Osaka 565-0871, Japan' and Discovery Research Laboratory, Tanabe Seiyaku Co. Ltd., \\ 2-50, Kawagishi-2-chome, Toda, Saitama 335-8505, Japan ${ }^{2}$
}

Received 15 October 2001/Accepted 19 November 2001

\begin{abstract}
A family I.3 lipase from Pseudomonas sp. MIS38 (PML) contains 12 repeats of a nine-residue sequence motif in the $\mathrm{C}$-terminal region. To elucidate the role of these repetitive sequences, $\mathrm{mu}$ tant proteins PML5, PML4, PML1, and PML0, in which 7, 8, 11, and all 12 of the repetitive sequences are deleted, and PMLA19, in which $19 \mathrm{C}$-terminal residues are truncated, were constructed. Escherichia coli DH5 cells carrying the Serratia marcescens Lip system permitted the secretion of the wild-type and all of the mutant proteins except for PMLA19, although they were partially accumulated in the cells in an insoluble form as well. Both the secretion level and cellular content of the proteins decreased in the order PMI $>$ PMI 5 > PML 4 $>$ PMI.1 $>$ PMLO, indicating that repetitive sequences are not required for secretion of PML but are important for its stability in the cells. All the mutant proteins were purified in a refolded form and their biochemical properties were characterized. CD spectra, the $\mathrm{Ca}^{2+}$ contents, and susceptibility to chymotryptic digestion strongly suggested that the five repetitive sequences remaining in PML5 are sufficient to form a $\beta$-roll structure, whereas the four in PML4 are not. PML5 and PMLA19 showed both lipase and esterase activities, whereas PML4, PML1, and PML0 were inactive. These results suggest that the enzymatic activity of PML is not seriously affected by a deletion or truncation at the $C$-terminal region as long as a succession of repetitive sequences can build a $\beta$-roll structure.
\end{abstract}

[Key words: lipase, mutation, protein conformation, secretion, Pseudomonas sp., Serratia marcescens Lip]

Family I.3 lipases, which are represented by lipases from Pseudomonas fluorescens (LipA $\mathrm{PP}_{\mathrm{PF}}$ ) and Serratia marcescens $\left(\operatorname{Lip} A_{S M}\right)$, are distinguished from other lipases not only by their amino acid sequences but also by their secretion mechanism $(1,2)$. They are secreted from gram-negative bacteria through both inner and outer membranes by a three-component ATP-binding cassette (ABC) transporter system (3-5). A hydrophobic five-residue sequence located between the 19 th and 15 th residues from the C-terminus of LipA $_{\mathrm{SM}}$, has been identified as a secretion signal (6).

Family I.3 lipases $(7,8)$, as well as most other proteins secreted by $\mathrm{ABC}$ transporters, such as Escherichia coli hemolysin (HlyA) (9), Erwinia chrysanthemi protease B (PrtB) (10), and Pseudomonas aeruginosa alkaline protease $\left(A p r A_{P A}\right)(11)$, contain several repeats of a nine-residue GGXGXDXUX sequence motif (X, any amino acid; $U$, large hydrophobic amino acid) in the upstream region of a C-terminal secretion signal (Fig. 1). According to the crystal structures of $\operatorname{Apr}_{\mathrm{PA}}(12,13)$ and $S$. marcescens metalloprotease (PrtA $\left.A_{S M}\right)(14,15)$, these repetitive sequences form a parallel $\beta$-roll structure (two repeats per one roll), to which

* Corresponding author. e-mail: kanaya(a)ap.chem.eng.osaka-u.ac.jp phone/fax: +81-(0)6-6879-7938
5-6 $\mathrm{Ca}^{2+}$ ions bind. The first six residues of this sequence motif form a loop and the last three form a $\beta$-strand. Each $\mathrm{Ca}^{2+}$ ion binds between a pair of these loops. The role(s) of these repetitive sequences remains to be fully understood. From analyses of the secretion of mutant proteins of HlyA (16) and PrtB (17), which lack most of the repetitive sequences, and their enzymatic activities in the culture supernatant and cell extracts, it has been suggested that the repetitive sequences are not required for secretion but are needed for activity. However, it remains to be determined whether deletion of these repetitive sequences seriously affects protein conformation and/or secretion efficiency. It has also yet to be elucidated whether all of the repetitive sequences are required for activity.

A lipase from Pseudomonas sp. MIS38 (PML), a member of family I.3, is composcd of 617 amino acid residues (18). It shows amino acid sequence identities of $60.8 \%$ to $\mathrm{LipA}_{\mathrm{SM}}$ and $57.4 \%$ to $\operatorname{LipA}_{\mathrm{PF}}$ and contains 12 repeats of a nine-residue sequence motif in the C-terminal region (Fig. 1). Recombinant PML is overproduced in $E$. coli in inclusion bodies, solubilized in a buffer containing $8 \mathrm{M}$ urea, and refolded in the presence of the $\mathrm{Ca}^{2+}$ ion (18). The enzyme is active only in a holo-form, in which $\sim 12 \mathrm{Ca}^{2+}$ ions bind. Site-directed mutagenesis studies have revealed that $\mathrm{Ser}^{207}, \mathrm{Asp}^{255}$, 


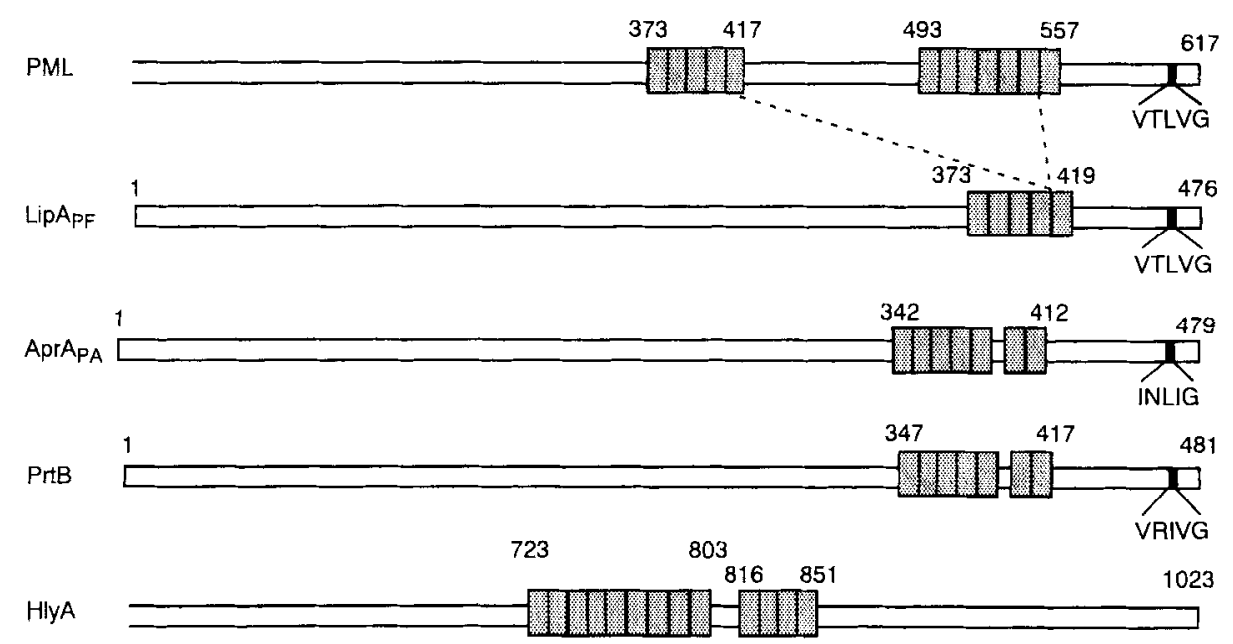

FIG. 1. Localization of a typical sequence motif in the C-terminal regions of the proteins. The primary structures of representative pruleins secreted by $\mathrm{ABC}$ transporters are schematically depicted. The PML sequence has a 138-residue peptide $\left(\mathrm{Val}^{406}-\mathrm{Asp}^{543}\right)$ insertion between $\mathrm{Asn}{ }^{405}$ and $\mathrm{Thr}^{406}$ of LipA $\mathrm{PF}_{\mathrm{PF}}$ The nine-residue GGXGXDXUX sequence motif is represented by a shaded box. A hydrophobic five-residue sequence motif, which has been proposed to be a secretion signal (6), is shown as a black box. Numbers indicate the positions of the amino acid residues starting from the initial methionine residue. PML, Pseudomonas sp. Mis38 lipase (DDBJ AB025596); LipA $A_{\mathrm{PF}}$ P. fluorescens lipase (GenBank AF083061); $\mathrm{Apr}_{\mathrm{PA}}, P$. aeruginosa alkaline protease (PIR S26699); PrtB, E. chrysanthemi protease B (GenBank J04736); HlyA, E. coli hemolysin (PIR P09983).

and $\mathrm{His}^{313}$ form a catalytic triad (19). Limited proteolysis of recombinant PML produces an N-terminal fragment (1370 ) and a C-terminal fragment (371-617), which respectively contain all of the catalytic residues and repetitive sequences. These findings suggest that PML consists of an Nterminal catalytic domain and a $\mathrm{C}$-terminal $\beta$-roll domain, like $\operatorname{AprA}_{\mathrm{PA}}$ (12) and $\operatorname{PrtA}_{\mathrm{SM}}$ (14).

In the work reported here, we constructed four mutant proteins of PML, in which 7, 8,11, and all 12 of the repetitive sequences are deleted, as well as a mutant protein with a C-terminal 19-residue truncation, and analyzed their secretion by using recombinant $E$. coli cells carrying the $S$. marcescens $\mathrm{ABC}$ transporter system (Lip system). We also purified these mutant proteins and analyzed their biochemical properties. Based on the results, we discuss possible roles of the repetitive sequences of PML.

\section{MATERIALS AND METHODS}

Cells and plasmids The Escherichia coli strains used were DH5 $\left[\mathrm{F}^{-}, h s d R 17\left(\mathrm{r}_{\mathrm{K}}{ }^{-}, \mathrm{m}_{\mathrm{K}}{ }^{+}\right)\right.$, recAl, endAldeoR, thi-1, supE44,

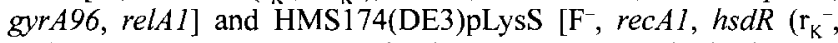
$\mathrm{m}_{\mathrm{K}}{ }^{+}$) RifR (DE3) pLysS $\left(\mathrm{Cm}^{r}\right)$ ]. Plasmid pYBCD20 harboring the lipBCD gene from Serratia marcescens SM8000 (20) and the plasmid $\mathrm{pET}-25 \mathrm{~b}(+)$ derivative ( $\mathrm{pET}-\mathrm{PML}$ ) for overproduction of PML (18) were previously constructed. Plasmid pUC18 was from loyobo (Kyoto) and $\mathrm{pEI}-25 \mathrm{~b}(+)$ was from Novagen (Madison, WI, USA).

Plasmid construction Plasmids pUC-PML, pUC-PML5, pUCPML4, pUC-PML1, pUC-PML0, and pUC-PML 19 for secretion of PML, PML5, PML4, PML1, PML0, and PMLA19 (Fig. 2), respectively, were constructed by the following procedures. The PML gene (lipA) was amplified by PCR using primer 1 ( $5^{\prime}-\mathrm{GCCC}$ GGAATTCATATGGGT-GTGTATGACTA- $\left.3^{\prime}\right)$ and primer $2\left(5^{\prime}-\mathrm{TC}\right.$ A-AAGCTTTCAGGCGATCACAATTCCAT-CGGC-3'). Plasmid pET-PML was used as a template. Likewise, the gene encoding PML 19 was amplificd by PCR using primer 1 and primer $3\left(5^{\prime}-\mathrm{C}\right.$ CAAGCTTAGCGCTTCACGAATCCCCGCCAAAC-3'). Under- lines in these sequences represent the EcoRl and $N d e I$ sites for primer 1, the HindIII site for primer 2, and the HindIII and Eco47III sites for primer 3 . The genes encoding PML5, PML4, and PML1 were amplified by performing PCR twice using primers 1 and 2, and $5^{\prime}$ - and $3^{\prime}$-mutagenic primers (see below). Two primary PCR products were first generated. One was generated with primer 1 and the $3^{\prime}$-mutagenic primer, and the other with the $5^{\prime}$ mutagenic primer and primer 2. These two PCR products were mixed and the secondary PCR product was amplified using only primers 1 and 2. The $5^{\prime}$-mutagenic primers for amplification of the gencs encoding PML5, PML4, PML1, and PML0 were 5'-CGGT GGTGGCTACAACACGTTCCTGTTCAACGGCGCG-3', 5'-AG TACTTTCATCATCGGCGGCAGCGGCAAG-3', 5'-AGTACTT TCATCATCTTCAACGGCGCGTTC-3', and 5'-AGTACTTTCAT CATCGGTTTTACGTCGAAC-3', respectively. The $3^{\prime}$-mutagenic primers were complementary to these primers. The PCR products were digested with EcoRI and HindIII and ligated into the EcoRIHindlII sites of pUC18.

Plasmids pET-PML5, pET-PML4, pET-PML1, pET-PML0, and pET-PML $\Delta 19$ for overproduction of PML5, PML.4, PML1, PML0, and PML $\Delta 19$, respectively, were constructed by digesting the plasmid pUC18 derivatives with $N d e I$ and HindIII, followed by ligation of the resultant $N d e$ I-HindIII fragments into the $N d e$ I-HindIII sites of pET-25b(+).

PCR was performed in 30 cycles using a thermal cycler (GeneAmp PCR System 2400; Perkin-Elmer, Tokyo) and Vent polymerase (New England Biolabs, Beverly, MA, USA). The nucleotide sequences of the genes encoding mutant proteins were confirmed with an ABI PRISM 310 Genetic Analyzer (Perkin-Elmer).

Secretion E. coli DH5 cells were first transformed with plasmid pYBCD20 and then with a pUC18 derivative. The resultant recombinant cells carrying the two different plasmids were grown in LB medium (21) containing $50 \mu \mathrm{g} / \mathrm{ml}$ ampicillin and $30 \mu \mathrm{g} / \mathrm{ml}$ chloramphenicol at $30^{\circ} \mathrm{C}$ for $24 \mathrm{~b}$ with vigorous shaking. The $S$. marcescens lip $B C D$ gene and the gene encoding PML or mutant PML were constitutively expressed in these recombinant cells. The culture was then centrifuged at $15,000 \times \mathrm{g}$ for $10 \mathrm{~min}$ at $4^{\circ} \mathrm{C}$ to separate the cells and the supernatant. The cells were washed once with $50 \mathrm{mM}$ Tris- $\mathrm{HCl}(\mathrm{pH} 7.5)$ and dissolved in $0.1 \mathrm{M}$ Tris- $\mathrm{HCl}$ (pH 6.8) containing $2 \%$ SDS, $5 \%(\mathrm{v} / \mathrm{v}) \beta$-mercaptoethanol, $10 \%$ 
(v/v) glycerol, and $0.02 \%$ bromophenol blue (SDS sample buffer) to yield a whole cell extract. To estimate the amounts of the proteins accumulated intracellularly and secreted into the external medium, the culture supernatant and whole cell extract were analyzed by SDS-PAGE (22) on a $12 \%$ polyacrylamide gel, followed by staining with Coomassie brilliant blue (CBB). Because the concentrations of the proteins in the culture supernatant were too low to be detected by $\mathrm{CBB}$ staining, these proteins were precipitated by $70 \%(\mathrm{v} / \mathrm{v})$ acetone and dissolved in the SDS sample buffer at a concentration sufficient for detection by CBB staining.

Overproduction, purification, and refolding $E$. coli HMS 174(DE3)pLysS cells were transformed with pET-25b $(+)$ derivatives and grown in L-broth containing $50 \mu \mathrm{g} / \mathrm{ml}$ ampicillin at $37^{\circ} \mathrm{C}$. Overproduction of the mutant proteins of PML in inclusion bodies, solubilization and purification in the presence of $8 \mathrm{M}$ urea, and refolding in the presence of the $\mathrm{Ca}^{2+}$ ion were done as previously described for recombinant PML (18).

Gel filtration Gel-filtration chromatography was carried out using a column $(\$ 2.2 \times 95 \mathrm{~cm})$ of Sephacryl S-300 (Amersham Pharmacia Biotech, Piscataway, NJ, USA) equilibrated with 20 $\mathrm{mM}$ Tris- $\mathrm{HCl}(\mathrm{pH} 7.5)$ containing $150 \mathrm{mM} \mathrm{NaCl}$. To estimate the molecular weights of the proteins, bovine serum albumin $(67 \mathrm{kDa})$, ovalbumin $(43 \mathrm{kDa})$, chymotrypsinogen $\mathrm{A}(25 \mathrm{kDa})$, and RNase $A$ $(13.7 \mathrm{kDa})$ were used as standards.

Protease digestion The protein was digested with chymotrypsin at $25^{\circ} \mathrm{C}$ for $10 \mathrm{~min}$ in $10 \mathrm{mM}$ Tris- $\mathrm{HCl}(\mathrm{pH} 8.0)$ containing $2.5 \mathrm{mM}$ dithiothreitol (DTT) at substrate: enzyme ratios of $50: 1$ $500: 1$ (by weight). Degradation of the protein was analyzed by $12 \%$ SDS-PAGE, followed by CBB staining.

Enzymatic activity The lipase and esterase activities were determined in $25 \mathrm{mM}$ Tris- $\mathrm{HCl}\left(\mathrm{pH} \mathrm{7.5)}\right.$ at $30^{\circ} \mathrm{C}$ using olive oil and $p$-nitrophenyl laurate $\left(\mathrm{C}_{12}\right)$ respectively as the substrate, as described previously (18). One unit of enzymatic activity was defined as the amount of enzyme that liberated $1 \mu \mathrm{mol}$ of fatty acid or $p$-nitrophenol per min. The specific activity was defined as the enzymatic activity per $\mathrm{mg}$ of protein. The protein concentration was determined from UV absorption using an $A_{280} 0^{n \%}$ value of 1.1 for PML, and 1.2 for PML5, PML4, PML1, PML0, and PML 19 , which were calculated using $1576 \mathrm{M}^{-1} \mathrm{~cm}^{-1}$ for Tyr and $5225 \mathrm{M}^{-1}$ $\mathrm{cm}^{-1}$ for Trp at $280 \mathrm{~nm}$ (23). E. coli DH5 transformants with plasmid pYBCD20 and a pUC18 derivative were also examined for lipase production by in situ plate assay. The transformants were grown on LTB-agar medium (L broth supplemented with $1 \%(\mathrm{v} / \mathrm{v})$ tributyrin, $0.1 \%(\mathrm{v} / \mathrm{v})$ Tween $80,50 \mu \mathrm{g} / \mathrm{ml}$ ampicillin, $30 \mu \mathrm{g} / \mathrm{ml}$ chloramphenicol, and $1.5 \%$ agar) and the plate was examined for the formation of a clear halo around the colonies.

Circular dichroism Far-IIV (200-260 nm) and near-LIV (250$310 \mathrm{~nm}$ ) CD spectra were measured in $10 \mathrm{mM}$ Tris- $\mathrm{HCl}(\mathrm{pH} 7.5)$ containing $10 \mathrm{mM} \mathrm{CaCl}_{2}$ at $20^{\circ} \mathrm{C}$ on an automatic spectropolarimeter (model J-725; Japan Spectroscopic, Tokyo). The protein concentration and optical path length were $0.1 \mathrm{mg} / \mathrm{ml}$ and $2 \mathrm{~mm}$ for far-UV CD spectra, and $1.0 \mathrm{mg} / \mathrm{ml}$ and $10 \mathrm{~mm}$ for near-UV CD

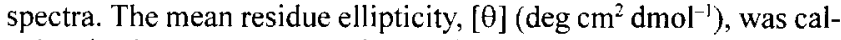
culated using an average amino acid molecular weight of 110 .

Western blot (immunoblot) analysis Western blotting was done as described previously (24). Proteins were subjected to SDS-PAGE on a $12 \%$ polyacrylamide gel and electrophoretically transferred to a PVDF membrane (Bio-Rad, Tokyo). The blots were blocked by soaking in 5\% skim milk (Difco Laboratories, Detroit, MI, USA) in $25 \mathrm{mM}$ Tris- $\mathrm{HCl}$ (pH 7.5) containing $0.5 \mathrm{M}$ $\mathrm{NaCl}$ and incubated with antisera (diluted 1:100), which was previously produced against $S$. marcescens lipase $\left(\operatorname{LipA}_{\mathrm{SM}}\right)$ (7). Signals were detected with horseradish peroxidase-conjugated antirabbit immunoglobulin $\mathrm{G}$.

\section{RESULTS}

Mutant design PML is similar in size to $\mathrm{LipA}_{\mathrm{SM}}$ but much larger than $\mathrm{LipA}_{\mathrm{PF}}$. Comparison of the amino acid sequence of PML with that of $\operatorname{LipA}_{\mathrm{PF}}$ reveals that the PML sequence has a 138-residue insertion in the C-terminal region where a putative nine-residue sequence motif is repeated (Fig. 1). If this insertion is excluded, PML shows an amino acid sequence identity of $74.4 \%$ to $\operatorname{LipA}_{\mathrm{PF}}$. Since this insertion contains seven repetitive sequences, Lip $_{\mathrm{PF}}$ contains only five such sequences in total at positions 373-405. Thus, PML and Lip $A_{P F}$ differ considerably in the number of their repetitive sequences. This raises the question whether the repetitive sequences can be reduced from 12 to 5 , or less than 5 , without seriously affecting the secretion efficiency and/or the enzymatic activity of PML. Therefore, we constructed the mutant proteins PML5, PML4, PML1, and PMLO (Fig. 2) and examined their secretion and enzymatic activities. PML5 lacks the 138-residue insertion (residues 406-543) and therefore contains five repetitive sequences like LipA $A_{P F}$. PML4 lacks the first repetitive sequence (residues 373-381) in addition to the 138-residue insertion, and thus contains four repetitive sequences. PML1 and PML0 lack the initial 11 (residues 373-546) and all 12 (residues 373-557) of the repetitive sequences, respectively. In addition, we constructed the mutant protein PML $\Delta 19$, in which 19 C-terminal residues are truncated, to examine whether it is not secreted into the medium but is enzymatically active. PML 19 does not contain a secretion signal which, according to a recent report by Omori et al. (6), is located at positions 19-15 from the C-terminus of PML.

PML secretion system To examine whether E. coli DH5 cells carrying the $S$. marcescens Lip system (20) can be used to secrete PML, these cells were transformed with the plasmid pUC-PML. The resultant recombinant cells grew rather poorly and the $\mathrm{OD}_{600}$ value of the culture reached only 1.3 even in the stationary phase. Protein analysis in the culture supernatant and whole cell extracts by SDS-PAGE indicated that a relatively large portion of the PML was secreted into the external medium, while the rest accumulated intracellularly (Fig. 3). Sonication lysis of the cells followed by centrifugation and SDS-PAGE revealed that PML accumulated intracellularly in an insoluble form (data not shown). From the intensities of the bands visualized by CBB staining, the amounts of PML secreted into the external medium and accumulated insolubly in the cells were estimated to be roughly 50 and $30 \mathrm{mg} / \mathrm{l}$ culture, respectively. In contrast, when $E$. coli $\mathrm{DH} 5$ cells not carrying the Lip system were transformed with pUC-PML, PML was not secreted into the external medium but accumulated intracellularly in an insoluble form. The secretion of PML is thus dependent on the Lip system.

PML was purified from the culture supernatant by applying an aliquot of it onto a gel-filtration column. PML was eluted from the column as a single peak. It gave a single band on SDS-PAGE and had the same far-UV and near-UV $\mathrm{CD}$ spectra as the refolded protein (data not shown). The molecular weights of PML estimated by gel-filtration chromatography and SDS-PAGE were 68,000 and 66,000 , respectively, suggesting that, like the refolded protein, it ex- 
Protein

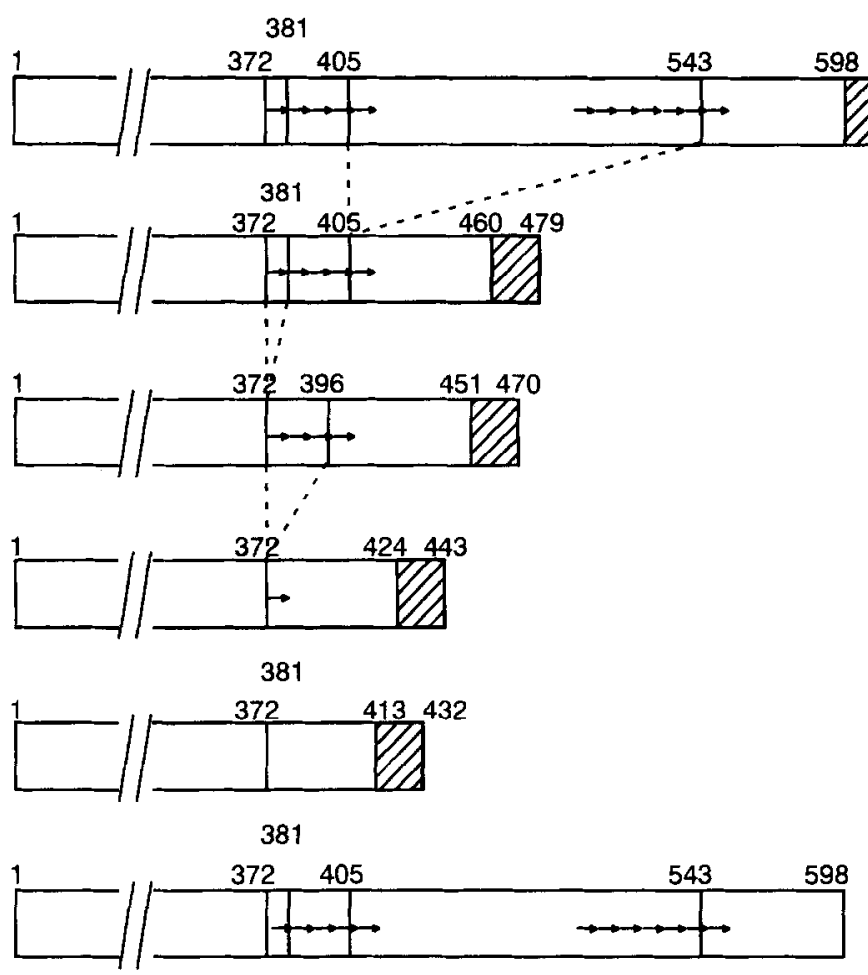

Name

$\underset{\substack{\text { External Internal } \\ \text { (mg/iter culture) }}}{\cos }$

PML

50

30

PML5 25

20

PML4 $\quad 12 \quad 7.0$

$\begin{array}{lll}\text { PML1 } & 2.5 & 0.1\end{array}$

$\begin{array}{lll}\text { PMLO } & 1.2 \quad 0.05\end{array}$

PML $19<0.03 \quad 0.3$

FIG. 2. Schematic representations of the primary structures of PML and its mutant proteins. Numbers indicate the positions of the amino acid residues located at the $\mathrm{C}$-terminus of each sequence block, except for that for the initial methionine residue. Each arrow represents the nine-residue GGXGXDXUX sequence motif. The amounts of proteins secreted into the external medium (external) and accumulated within the cells (internal), which were estimated from the intensities of bands visualized by Coomassie brilliant blue staining or immunoblotting analysis following SDSPAGE, are also shown.

ists in a monomeric form. The specific activity of the secreted protein was determined to be $4200 \pm 300$ units/mg (average of values obtained from two independent experiments) using olive oil as a substrate. The specific activity of the refolded protein for the hydrolysis of olive oil was previously reported to be 2800 units/mg (18), indicating that the specific activity of the secreted protein is $50 \%$ higher than that of the refolded one.

Secretion of mutant proteins Secretion of the mutant proteins was examined by using $E$. coli $\mathrm{DH} 5$ cells carrying the Lip system. As with PML, larger portions of PML5, PML4, PML1, and PML0 were secreted into the external medium than were accumulated intracellularly (Fig. 3). However, both the level of secretion and the cellular content
(A)

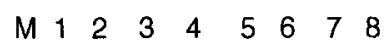

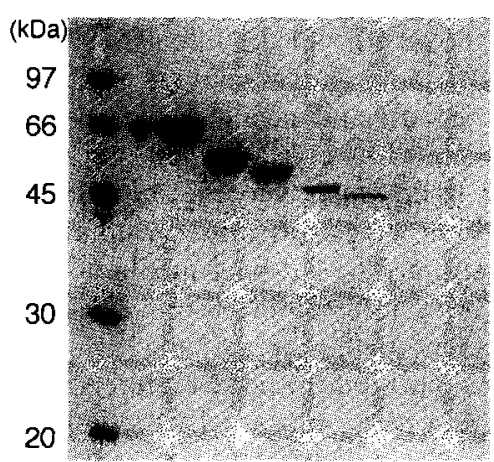

(B)

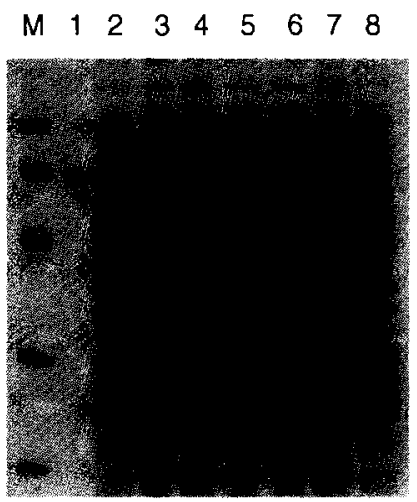

(C)

$$
\begin{array}{llllllll}
1 & 2 & 3 & 4 & 5 & 6 & 7 & 8
\end{array}
$$

FIG. 3. SDS-PAGE analysis of proteins secreted into the external medium and accumulated in cells. Recombinant $E$. coli DH5 cells were cultivated and the culture supernatant and whole cell extract were prepared as described in Materials and Methods. The culture supernatant (A) and whole cell extract $(\mathrm{B}, \mathrm{C})(100 \mu \mathrm{l}$ culture equivalent each) were applied to $12 \%$ SDS-PAGE. The gels were stained with Coomassie brilliant blue (A, $B$ ) or analyzed by immunoblotting with antisera against $\operatorname{LipA}_{S M}(C)$. M, A low molecular weight marker kit (Amersham Pharmacia Biotech); lane 1, purificd PML $(1 \mu \mathrm{g})$; lanes 2-7, E. coli DH5 carrying plasmids pYBCD20 and pUC-PML (lane 2), pUC-PML5 (lane 3), pUC-PML4 (lane 4), pUC-PMLI (lane 5), pUC-PML0 (lane 6), pUC-PML 19 (lane 7), or pUC18 (lane 8). 
of the proteins, which are summarized in Fig. 2, decreased in the order PML $>$ PML5 $>$ PML4 $>$ PML $1>$ PML0. The secretion level and the cellular content of PML0 were 50- and 600-fold lower than those of PML. In contrast, PMLA19 was not secreted into the external medium but it did accumulate in the cells (Fig. 3), - probably because this mutant does not contain a secretion signal. Its absence from the culture supernatant was confirmed by immunoblotting analysis (data not shown). The amount of PML $\Delta 19$ that accumulated in the cells was 100-fold lower than that of PML.

Purification of mutant proteins The mutant proteins were overproduced in E. coli HMS174(DE3)pLysS cells transformed with pET-25b(+) derivatives in inclusion bodies, solubilized and purified in the presence of $8 \mathrm{M}$ urea, and refolded in the presence of the $\mathrm{Ca}^{2+}$ ion. The production levels of PML5, PML4, PML1, and PML0 were comparable to that of PML (roughly $50 \mathrm{mg} / /$ culture), whereas that of PML $\Delta 19$ was 2-3 times lower (Fig. 4). All these mutant proteins were purified to give a single band on SDS-PAGE with a yield of approximately $70 \%$ (data not shown). The molecular weights of PML5, PML4, PML1, PML0, and PML $\Delta 19$ were respectively estimated to be $51,000,49,000$, $45,000,44,000$, and 64,000 from SDS-PAGE, which are comparable to those calculated from their amino acid sequences $(50,538$ for PML5, 49,591 for PML4, 47,177 for PML1, 45,660 for PML0, and 62,715 for PML 1 19). Gel-filtration chromatography suggested that all of these mutant proteins exist in a monomeric form. These refolded proteins were used for further biochemical characterization.

Enzyme activities The lipase and esterase activities of the refolded proteins, which were respectively determined at $30^{\circ} \mathrm{C}$ using olive oil and $p$-nitrophenyl laurate as the substrate, are summarized in Table 1. PML5 showed both lipase and esterase activities. The specific lipase and esterase activities of PML5 were roughly comparable to those of PML. In contrast, PML4, PML1, and PML0 showed neither lipase nor esterase activity. PMLA19 showed both lipase and esterase activities, but the specific activities were much lower

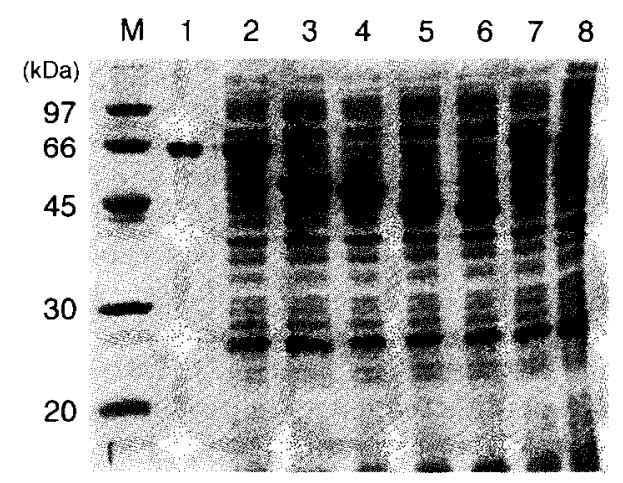

FIG. 4. SDS-PAGE analysis of overproduced proteins. PML and its mutant proteins were overproduced in E. coli HMS 174(DE3)pLysS cells transformed with plasmid $\mathrm{pFT}-25 \mathrm{~b}(+)$ derivatives as described in Materials and Methods. The whole cell extract $(50 \mu)$ culture equivalent) was applied to $12 \%$ SDS-PAGE. The gel was stained with Coomassie brilliant blue. M. A low molecular weight marker kit (Amersham Pharmacia Biotech); lane 1, purified PML (1 $\mu \mathrm{g})$; lanes 2-7,E. coli HMS 174(DE3)pLysS carrying plasmid pET-PML (lane 2), pETPML5 (lane 3), pET-PML4 (lane 4), pET-PML ? (lane 5), pET-PMLO (lane 6), pET-PMLA19 (lane 7), or pET-25b(+) (lane 8).
TABLE 1. Lipase and esterase activities of mutant proteins of PML

\begin{tabular}{|c|c|c|c|c|}
\hline \multirow[b]{2}{*}{ Protein } & \multicolumn{2}{|c|}{ Lipase } & \multicolumn{2}{|c|}{ Esterase } \\
\hline & $\begin{array}{l}\text { Specific } \\
\text { activity } \\
\text { (units/mg) }\end{array}$ & $\begin{array}{l}\text { Relative } \\
\text { activity } \\
(\%)\end{array}$ & $\begin{array}{l}\text { Specific } \\
\text { activity } \\
\text { (units/mg) }\end{array}$ & $\begin{array}{c}\text { Relative } \\
\text { activity } \\
(\%)\end{array}$ \\
\hline PML & 2800 & 100 & 84 & 100 \\
\hline PML5 & 3700 & 130 & 68 & 81 \\
\hline PML4 & $<10$ & $<0.3$ & $<0.05$ & $<0.06$ \\
\hline PMLI & $<10$ & $<0.3$ & $<0.05$ & $<0.06$ \\
\hline PML $\triangle 19$ & 230 & 8.2 & 7.6 & 9.0 \\
\hline
\end{tabular}

The lipase and esterase activities were respectively determined at $30^{\circ} \mathrm{C}$ using olive oil and $p$-nitrophenyl laurate as the substrate as described in Materials and Methods. The experiment was carried out in duplicate; errors lor the average values were within $9 \%$ and $6 \%$ of the values reported for the lipase and esterase activities, respectively. The relative activity was calculated by dividing the specific activity of the mutant protein by that of PML.

than those of PML.

The enzymatic activities of these mutant proteins were further confirmed by an in situ plate assay using an LTBagar plate. If $E$. coli transformants producing lipase or esterase grew on the plate, a halo would be formed around each colony due to the hydrolysis of tributyrin emulsified in the LTB-agar medium by the enzyme. When recombinant $E$. coli DH5 cells carrying the plasmid pYBCD20 and a pUC18 derivative were grown on the plate, those secreting PML and PML5 gave a clear halo, whereas those secreting PML4, PML1, and PML0 gave no halo at all. Recombinant cells producing PML $\wedge 19$ gave a weak halo, despite the fact that this mutant protein accumulated only intracellularly, which was probably due to leakage from the cells.

CD spectra The near-UV CD spectra of the wild-type and all the mutant proteins were similar to one another (Fig. 5B), suggesting that the three-dimensional environments of the aromatic residues in the protein were not seriously affected by the mutations. In contrast, the far-UV CD spectra of the mutant proteins differed from that of PML (Fig. 5A), suggesting that the protein secondary structures were altered by the mutations. The spectrum of PML exhibited a broad trough with two minimum [ $\theta$ ] values of $-12,600$ at $209 \mathrm{~nm}$ and $-12,800$ at $216 \mathrm{~nm}$, whereas that of PML5 had a trough with a minimum $[\theta]$ value of $-13,000$ at $208 \mathrm{~nm}$ followed by a shoulder with a $[\theta]$ value of 11,000 at $220 \mathrm{~nm}$. The spectrum of PML4 was similar to that of PML5 in the depth of the trough at $208 \mathrm{~nm}$, but the shoulder at around $220 \mathrm{~nm}$ was higher than that of PML5. The spectra of PML1 and PML0 were basically identical to that of PML4 and the spectrum of PML $\Delta 19$ was very similar to that of PML5.

$\mathrm{Ca}^{2+}$ content The number of the $\mathrm{Ca}^{3+}$ ions which remained bound to the protein after extensive dialysis was determined to be $11.3 \pm 0.5$ for PMI, $5.0+0.2$ for PML5, $1.8 \pm 0.2$ for PML4, $1.6 \pm 0.2$ for PML1, and $1.4 \pm 0.2$ for PML0, and $6.5 \pm 0.2$ for PML $\Delta 19$ by atomic absorption spectrometry on a Jarrel-Ash A-8500 Mark II spectrometer. These values represent an average of the values obtained from two independent experiments.

Stability PML, PML5, and PML $\Delta 19(0.01 \mathrm{mg} / \mathrm{ml})$ were incubated in $20 \mathrm{mM}$ Tris- $\mathrm{HCl}(\mathrm{pH} 7.5)$ containing $10 \mathrm{mM}$ $\mathrm{CaCl}_{2}$ at $50^{\circ} \mathrm{C}$, and the remaining activities at $30^{\circ} \mathrm{C}$ were de- 

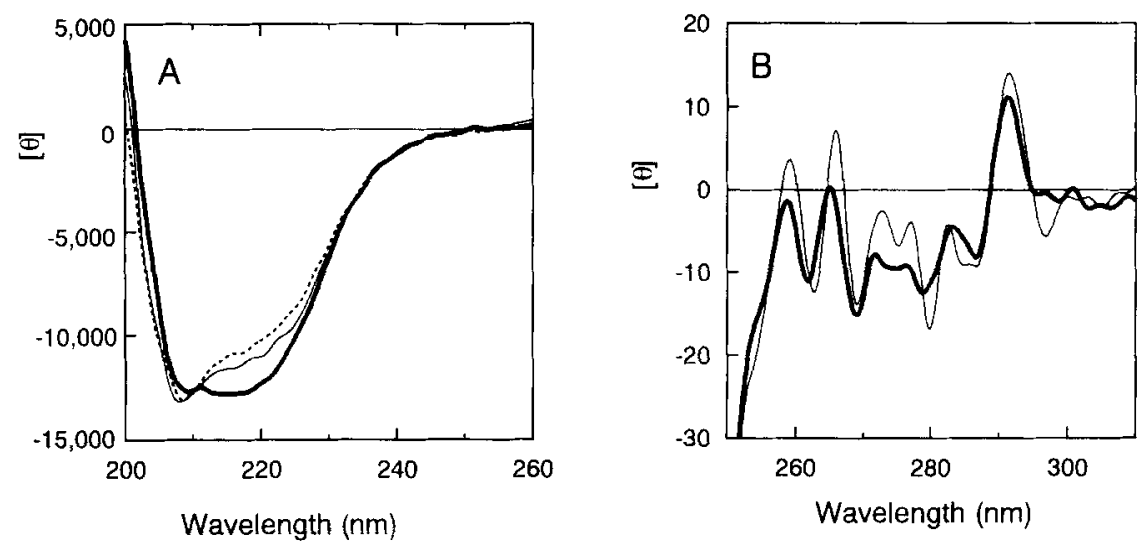

FIG. 5. CD spectra of wild-type and mutant proteins. The spectra of the wild-type and all the mutant protcins werc measurcd in $10 \mathrm{mM}$ Tris$\mathrm{HCl}(\mathrm{pH} 7.5)$ containing $10 \mathrm{mM} \mathrm{CaCl}$, at $20^{\circ} \mathrm{C}$ as described in Materials and Methods. (A) The far-UV CD spectra of PML (thick line), PML5 (thin line), and PML4 (broken line) are shown. The far-UV CD spectra of PML1, PML0, and PML 19 are not shown because the spectra of PML1 and PML0 were nearly identical to that of PML4 and the spectrum of PML 19 was almost the same as that of PML5. (B) The near-UV CD spectrum of PML1 (thin line), which exhibited the largest difference from that of PML (thick line), is shown as a representative spectrum. The mean residue ellipticity, $[\theta]$, is given in $\mathrm{deg}_{\mathrm{cm}}^{2} \mathrm{dmol}^{1}$.

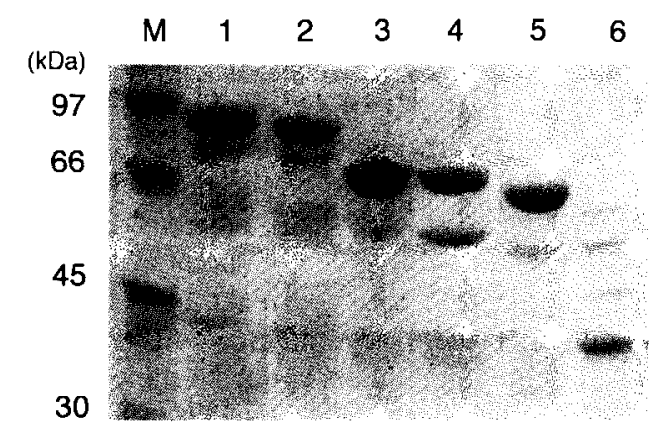

FIG. 6. Susceptibility of proteins to chymotryptic digestion. Proteins were digested with chymotrypsin at $25^{\circ} \mathrm{C}$ for $10 \mathrm{~min}$ in $10 \mathrm{mM}$ Tris- $\mathrm{HCl}$ (pH 8.0) containing $2.5 \mathrm{mM}$ DTT at a substrate : enzyme ratio of 50:1 for PML (lane 2) and PML5 (lane 4), and 500:1 for PML4 (lane 6). Samples were applied to $12 \%$ SDS-PAGE, followed by CBB staining. M, A low molecular weight marker kit (Amersham Pharmacia Biotech): lane 1, undigested PML; lane 3, undigested PML5; lane 5 , undigested PML4.

termined at appropriate intervals using $p$-nitrophenyl laurate as a substrate. PML, PML5, and PMLA19 lost half of their activitics upon incubation for 20,15 , and $3 \mathrm{~min}$, respectively, indicating that PML5 and PML 19 are slightly and markedly less stable against heat inactivation than PML.

Susceptibility to chymotryptic digestion Upon digestion with chymotrypsin at $25^{\circ} \mathrm{C}$ for $10 \mathrm{~min}$ at a substrate: enzyme ratio of $50: 1$, roughly $80 \%$ and $50 \%$ respectively of the PML and PML5 molecules remained intact (Fig. 6). In contrast, most of the PML4 molecules failed to stay intact, even at a substrate: enzyme ratio of 500:1 (Fig. 6). Most of the PML 1, PMI 0, and PMI A19 molecules also did not remain intact upon chymotryptic digestion at a substrate:enzyme ratio of 500:1 (data not shown). These results indicate that the susceptibilities of PML4, PML1, PML0, and PML $\Delta 19$ to chymotryptic digestion are much higher than that of PML5, while PML5 itself is slightly more susceptible to chymotryptic digestion than PML.

\section{DISCUSSION}

Validity of using refolded proteins for characterization We used refolded proteins for biochemical characterization in this study because we were not able to purify all the mutant proteins secreted into the external medium. We could purify PML5 from the culture supernatant in the same manner as PMI by applying an aliquot of it onto a gel-filtration column. However, PML4, PML1, and PML0 could not be purified from the supernatant by the same procedure because their concentrations were too low. Precipitation of the proteins with ammonium sulfate, acetone, or ethanol was not effective in concentrating them because they were not solubilized in their native form once they were precipitated. Ultrafiltration was also ineffective because the culture supernatant contained various substances at relatively high concentrations. Purification by ion-exchange column chromatography was tried, but the proteins were not retained in either an anion-exchange or a cation-exchange column under any of the conditions examined. The specific activity of the refolded protein of PML is lower than but comparable to that of the secreted one, suggesting that PML is refolded into the native enzyme but with a yield of less than $100 \%$. In addition, in sofar as could be ascertained from the far- and near-UV CD spectra data, the refolded protein was structurally identical to the secreted one. These findings strongly suggest that the biochemical properties of the refolded proteins reflect those of the native ones.

Role of repetitive sequences in protein conformation When the far-UV CD spectra of PML, PML5, and PML4 are compared, it can be seen that the depth of the trough at $210-230 \mathrm{~nm}$ decreases in line with a reduction in the number of repetitive sequences in the protein (Fig. 5A). Because a typical spectrum for a $\beta$-structure gives a broad trough in this region with a minimum [ $\theta$ ] value at $218 \mathrm{~nm}(25)$, and the last three residues of each repetitive sequence form a $\beta$ strand in a $\beta$-roll structure, the decrease in the depth of the trough at $210-230 \mathrm{~nm}$ may result from a lower $\beta$-roll content in the protein. However, PML1 and PMLO showed the 
same spectrum as PML4, despite the absence of most or all of the repetitive sequences. These results suggest that in PML4, which contains four repetitive sequences, a $\beta$-roll structure is not formed, or is only poorly formed. The determinations of $\mathrm{Ca}^{21}$ ions bound to these proteins and their susceptibility to chymotryptic digestion support this hypothesis. When the $\mathrm{Ca}^{2+}$ contents of PML, PML5, and PML0 are compared, the $\mathrm{Ca}^{2+}$ content is observed to decrease in proportion to the reduction in the number of repetitive sequences. However, PML4 has a similar $\mathrm{Ca}^{2+}$ content to PML0. Likewise, when the susceptibility of each of the mutant proteins to chymotryptic digestion is compared with that of PML, the susceptibility of PML5 is seen to be rather similar to that of PML, whereas PML4, PML1, and PML0 have comparable susceptibilities, which are much higher than that of PML. It has been reported that digestion by protease proceeds mainly via the unfolded state of proteins (26). Because the equilibrium between the folded and unfolded states of the protein must be shifted so that the fraction of the unfolded state increases, when a part of the protein molecule is unfolded, the dramatic increase in the susceptibility of PML4 to chymotryptic digestion as compared to PML5 may result from an inability of PML4 to form a $\beta$ roll structure.

The near-UV CD spectra of PML5, PML4, PML1, and PML0 were similar to that of PML (Fig. 5B). Because the near-UV CD spectrum reveals the three-dimensional environments of aromatic residues and most of the aromatic residues (six out of eight tryptophan and 16 out of 20 tyrosine residues) are located in the putative $\mathrm{N}$-terminal catalytic domain of PML, these spectra may reflect the conformation of its $\mathrm{N}$-terminal catalytic domain. These results suggest that removal of the repetitive sequences alters the $\beta$ roll structure of PML without seriously affecting the conformation of its $\mathrm{N}$-terminal catalytic domain.

Role of repetitive sequences in enzymatic activity The lipase and esterase activities of PML5 were comparable to those of PML, indicating that the number of repetitive sequences in PML can be reduced to five without seriously affecting the enzymatic activity. In contrast, PML4 showed neither lipase nor esterase activity, indicating that removal of an additional single repetitive sequence inactivates the protein. As mentioned above, a $\beta$-roll structure seems to be fully formed in PML5, but poorly formed in PML4. Therefore, formation of a $\beta$-roll structure may be required to make the conformation of a putative $\mathrm{N}$-terminal catalytic domain functional. This conformational change may be too subtle to be detected by the near-UV CD spectra. A similar role has been proposed for the $\beta$-roll structure of $A$ pr $A_{P A}$ (27). This protease lost enzymatic activity by the mutation of Asp (to Ala), which is located within a repetitive sequence and provides a ligand for $\mathrm{Ca}^{2+}$ hinding. It has been suggested that denaturation or imperfect folding of the Cterminal domain affects folding of the $\mathrm{N}$-terminal catalytic domain. Likewise, HlyA lost hemolytic activity upon deletion of 11 of 13 repetitive sequences (16), probably because the conformation of a calalytic donain is slightly altered in the absence of a $\beta$-roll structure.

It is noted that the stability of PML5 against heat inactivation was slightly lower than, but comparable to, that of
PML, suggesting that the number of repetitive sequences in PML can be reduced to five without seriously affecting the protein stability as well.

Role(s) of repetitive sequences in secretion The fact that PMLO was secreted into the external medium indicates that the repetitive sequences are not required for secretion. However, we found that the repetitive sequences are important for the stability of the protein in the cells, because both the amount of the mutant protein secreted into the external medium and that accumulated in the cells decreased as the number of repetitive sequences in the mutant protein was reduced. If the repetitive sequences were not required for the stability of the protein in the cells, but were required to increase the secretion efficiency, the amount of the protein accumulated in the cells would increase as the number of repetitive sequences was reduced. Mutant proteins lacking most of the repetitive sequences may be highly unstable and rapidly degraded by proteases in the cells before they are recognized by the $\mathrm{ABC}$ transporters. It seems unlikely that the genes encoding these mutant proteins are poorly expressed, because all the genes encoding the mutant and wild-type proteins were expressed with comparable efficiencies when the pET system was used. It has been suggested that proteins secreted by ABC transporters are synthesized in the cells with an imperfectly folded structure in which the C-terminal domain is unfolded, secreted across the inner and outer membranes in this form, and finally refolded into a functional conformation in an extracellular medium upon the binding of $\mathrm{Ca}^{2-}$ ions to the $\mathrm{C}$-terminal domain $(12,28)$. If this is the case, the repetitive sequences may be required to increase the stability of the imperfectly folded structure.

Based on analyses of the ability of a C-terminal fragment of HlyA and PrtB to promote the secretion of passenger proteins (29-31), it has also been suggested that repetitive sequences are required to separate the C-terminal secretion signal from the passenger domain and thereby facilitate recognition of the signal by $\mathrm{ABC}$ transporters. The repetitive sequences may play such a role in PML as well.

The repetitive sequences of PML are not consecutive but are interrupted by a large peptide insertion (Fig. 1). Similarities in the enzymatic activity, stability, and secretion level between PML5 and PML suggest that this inserted sequence is not functionally important. However, it remains to be determined whether the PML repetitive sequences constitute a single large $\beta$-roll structure or two independent $\beta$-roll structures.

Roles of the 19 C-terminal residues Truncation of 19 C-terminal residues creates a mutant protein that lacks the ability to be secreted via the Lip system. In addition, it greatly affects the enzymatic activity, susceptibility to chymotryptic digestion, and stability of PML. Because the depth of the trough in the far-UV CD spectrum of PML $\triangle 19$ at $210-230 \mathrm{~nm}$ was less than that of PML (Fig. 5A) and only $6-7 \mathrm{Ca}^{2+}$ ions bound to it, a $\beta$-roll structure is probably not fully formed in PML $\Delta 19$. Thus, the $19 \mathrm{C}$-terminal residues are required not only for the secretion of PML but also to make the conformation of the protein fully functional. 


\section{REFERENCES}

1. Jaeger, K. E., Ransac, S., Dijkstra, B. W., Colson, C., van Heuvel, M., and Misset, O.: Bacterial lipases. FEMS Microbiol. Rev., 15, 29-63 (1994).

2. Arpigny, J. L. and Jaeger, K. E.: Bacterial lipolytic enzymes: classification and properties. Biochem. J., 343, 177183 (1999).

3. Duong, F., Soscia, C., Lazdunski, A., and Murgier, M.: The Pseudomonas fuorescens lipase has a $\mathrm{C}$-terminal secretion signal and is secreted by a three-component bacterial ABC-exporter system. Mol. Microbiol., 11, 1117-1126 (1994).

4. Akatsuka, H., Kawai, E., Omori, K., and Shibatani, T.: The three genes lip $B, \operatorname{lip} C$, and lipD involved in the extracellular secretion of the Serratia marcescens lipase which lacks an N-terminal signal peptide. J. Bacteriol., 177, 6381-6389 (1995).

5. Ahn, J. H., Pan, J. G., and Rhee, J. S.: Identification of the tliDEF ABC transporter specific for lipase in Pseudomonas fluorescens SIK W1. J. Bacteriol., 181, 1847-1452 (1999).

6. Omori, K., Idei, A., and Akatsuka, H.: Serratia ATP-binding cassette protein exporter, Lip, recognizes a protein region upstream of the $C$ terminus for specific secretion. J. Biol. Chem., 276, 27111-27119 (2001).

7. Akatsuka, H., Kawai, E., Omori, K., Komatsubara, S., Shibatani, T., and Tosa, T.: 'The lipA gene of Serratia marcescens which encodes an extracellular lipase having no N-terminal signal peptide. J. Bacteriol., 176, 1949-1956 (1994).

8. Li, X., Tetling, S., Winkler, U.K., Jaeger, K. E., and Benedik, M. J.: Gene cloning, sequence analysis, purification, and secretion by Escherichia coli of an extracellular lipase from Serratia marcescens. Appl. Environ. Microbiol., 61, 2674-2680 (1995)

9. Felmlee, T., Pellett, S., and Welch, R. A.: Nucleotide sequence of an Escherichia coli chromosomal hemolysin. J. Bacteriol., 163, 94-105 (1985).

10. Delepelaire, P. and Wandersman, C.: Protcase secretion by Erwinia chrysanthemi. Proteases B and C are synthesized and secreted as zymogens without a signal peptide. J. Biol. Chem., 264, 9083-9089 (1989).

11. Duong, F., Lazdunski, A., Cami, B., and Murgier, M.: Sequence of a cluster of genes controlling synthesis and secretion of alkaline protease in Pseudomonas aeruginosa: relationships to other secretory pathways. Gene, 121, 47-54 (1992).

12. Baumann, U., Wu, S., Flaherty, K. M., and McKay, D. B.: Three-dimensional structure of the alkaline protease of Pseudomonas aeruginosa: a two-domain protein with a calcium binding parallel beta roll motif. EMBO J., 12, 33573364 (1993).

13. Miyatake, H., Hata, Y., Fujii, T., Hamada, K., Morihara, K., and Katsube, Y.: Crystal structure of the unliganded alkaline protease from Pseudomonas aeruginosa IFO3080 and its conformational changes on ligand binding. J. Biochem. (Tokyo), 118, 474-479 (1995).

14. Baumann, U.: Crystal structure of the $50 \mathrm{kDa}$ metallo protease from Serratia marcescens. J. Mol. Biol., 242, 244-251 (1994).

15. Hamada, K., Hata, Y., Katsuya, Y., Hiramatsu, H., Fujiwara, T., and Katsube, Y.: Crystal structure of Serratia protease, a zinc-dependent proteinase from Serratia sp. E-15, containing a $\beta$-sheet coil motif at $2.0 \AA$ resolution. J. Biochem. (Tokyo), 119, 844-851 (1996).

16. Felmlee, T. and Welch, R. A.: Alterations of amino acid repeats in the Escherichia coli hemolysin affect cytolytic activity and secretion. Proc. Natl. Acad. Sci. USA, 85, 5269-5273 (1988).

17. Delepelaire, P. and Wandersman, C.: Protein secretion in gram-negative bacteria. The extracellular metalloprotease $\mathrm{B}$ from Erwinia chrysanthemi contains a C-terminal secretion signal analogous to that of Escherichia coli alpha-hemolysin. J. Biol. Chem., 265, 17118-17125 (1990).

18. Amada, K., Haruki, M., Imanaka, T., Morikawa, M., and Kanaya, S.: Overproduction in E. coli, purification, and characterization of a family I.3 lipase from Pseudomonas sp. MIS38. Biochim. Biophys. Acta, 1478, 201210 (2000).

19. Kwon, H-J., Amada, K, Haruki, M., Morikawa, M., and Kanaya, S.: Identification of the histidine and aspartic acid residues essential for enzymatic activity of a family 1.3 lipase by site-directed mutagenesis. FEBS Lett., 483, 139-142 (2000).

20. Kawai, E., Akatsuka, H., Idei, A., Shibatani, T., and Omori, K.: Serratia marcescens S-layer protein is secreted extracellularly via an ATP-binding cassette exporter, the Lip system. Mol. Microbiol., 27, 94 l-952 (1998).

21. Maniatis, T., Fritsch, E. F., and Sambrook, J.: Molecular cloning: a laboratory manual, p. 440. Cold Spring Harbor Laboratory Press, Cold Spring Harbor, NY (1982).

22. Laemmli, U.K.: Cleavage of structural proteins during the assembly of the head of bacteriophage T4. Nature, 227, 680685 (1970).

23. Goodwin, T. W. and Morton, R. A.: The spectrophotometric determination of tyrosine and tryptophan in proteins. Biochem. J., 40, 628-632 (1946).

24. Wong, S. W. and Wang, T. S.-F.: DNA polymerases alpha and delta are immunologically and structurally distinct. J. Biol. Chem., 264, 5924-5928 (1989).

25. Greenfield, N. and Fasman, G. D.: Computed circular dichroism spectra for the evaluation of protein conformation. Biochemistry, 8, 4108-4116 (1969).

26. Imoto, T., Yamada, H., and Ueda, T.: Unfolding rates of globular proteins determined by kinetics of proteolysis. J. Mol. Biol., 190, 647-649 (1986).

27. Miyajima, Y., Hata, Y., Fukushima, J., Kawamoto, S., Okuda, K., Shibano, Y., and Morihara, K.: Long-range effect of mutation of calcium binding aspartates [correction of asparates] on the catalytic activity of alkaline protease from Pseudomonas aeruginosa. J. Biochem. (Tokyo), 123, 24-27 (1998).

28. Sprang, S. R.: On a ( $\beta$-) roll. Trends Biochem. Sci., 18, $313-$ 314 (1993).

29. Kenny, B., Haigh, R., and Holland, I. B.: Analysis of the haemolysin transport process through the secretion from Escherichia coli of PCM, CAT or $\beta$-galactosidase fused to the Hly C-terminal signal domain. Mol. Microbiol., 5, 2557-2568 (1991).

30. Letoffe, S. and Wandersman, C.: Secretion of CyaA-PrtB and HlyA-PrtB fusion proteins in Escherichia coli: involvement of the glycine-rich repeat domain of Erwinia chrysanthemi protease B. J. Bacteriol., 174, 4920-4927 (1992).

31. Duong, F., Lazdunski, A., and Murgier, M.: Protein secretion by heterologous bacterial $\mathrm{ABC}$-transporters: the $\mathrm{C}$-terminus secretion signal of the secreted protein confers high recognition specificity. Mol. Microbiol., 21, 459-470 (1996). 